\title{
PAR'T' III.
}

\section{MEDICAL MISCELLANY.}

Keports, Transactions, and Scientific Intelligence.

ROYAL ACADEMY OF MEDICINE IN IRELAND.

President-Sir Charles Bald, F.R.C.S.I. General Secretary-J. A. ScotT, M.D., F.R.C.S.I.

SECTION OF MEDICINE.

President-Sir John Moore, M.D., F.R.C.P.I.

Sectional Secretary-F. C. Purser, M.D., F.R.C.P.I.

Friday, December 16, 1910.

The President in the Chair.

Coeliac Axis Aneurysm treated by Operation. Introduction of Wire Tent.

Dr. Lumsden showed a man, aged thirty-eight, brewery labourer, who had been engaged at a somewhat heavy class of work-piling casks. History of syphilis sixteen years ago. Served in the army sixteen years. Dyspeptic symptoms since beginning of year. Abnormal epigastric pulsation first noticed last August on admission to Mercer's Hospital. In September last a tumour the size of an orange felt in epigastrium extending upwards under left costal arch. Impulse of a forcible and expansile character. A bruit heard below lump and conveyed along aorta to both femorals. Femoral pulses readily to be felt. Heart normal but for accentuation of aortic second sound. Pulse tension trifle high. Blood pressure in radial $110 \mathrm{~m} . \mathrm{m}$. Hg. No pains of any kind complained of. Diagnosis was saccular aneurysm of aorta probably from coliac axis neighbourhood. Patient. 
was placed on large doses of iodide of potassium, complete rest in recumbent position with a modified Tufnell's diet;. No improvement taking place, after consultation with $\mathrm{Mr}$. Wheeler operation was decided on.

\section{Operation for Abdominal Aneurysm.}

MR. W. I. DE C. WhEELER described the evolution of surgery of the abdominal aneurysm. The case exhibited resembled the vast majority in being a male, having a specific history and having the aneurysm springing from the region of the cœliac axis.

Mr. Wheeler operated seven weeks ago and introduced into the sac 150 inches of gilded wire in the form of a cage by the method of Colt and D'Arcy Power. For the first few days the aneurysmal pulsation was more tumultuous than before the operation, but since then there has been a distinct diminution of pulsation and hardening of the tumour.

The operation was performed with the strictest asepticprecautions, and was facilitated by placing a sand-bag under the patient's back and tilting the table so that the pelvis and feet were low, and the intestines fell away into the pelvis (Mayo Robson's gall-bladder position). There was no hemorrhage.

Mr. Wheeler pointed out that statistics demonstrated a small percentage of cures in the cases operated upon, but that the prognosis was hopeless when operation was not possible, Osler and other authorities never having seen a cure under medical treatment. Post-mortem examinations of cases which died even a short time after operation revealed a firm, laminated clot in which the wire was embedded.

Electrolysis was not employed in this case, as there is not sufficient experimental evidence of its value in inducing coagulation. The risk of sepsis is increased owing to the prolongation of the operation and the difficulty of sterilisation of insulated instruments and electrical apparatus.

Colt's instrument makes the operation very easy and very safe.

In conclusion $\mathrm{Mr}$. Wheeler referred to the differential diagnosis and the causes of failure in many of the early operations. His was the first patient exhibited in Dublin after operation for abdominal aneurysm. 
Dr. Walter Smith said the case was, as far as he knew, the first demonstrated in Dublin. The main subject for congratulation was that the patient had survived, though living after an operation was no proof that it prolonged life, and patients had lived with an untreated aneurysm. He hoped none of his friends would ever introduce wire into his aorta, as he considered the operation both unpathological and unscientific. The only chance of cure was by nature laying down tough, laminated fibrin. A foreign body might induce embolism, and was very dangerous.

Dr. Parsons recalled a case in which the symptoms began in 1896, and the patient did laborious work until within two years of his death in 1906 . He thought the chances of repeating such a successful result as Mr. Wheeler's were very small.

Dr. Kirkpatrick said he believed the patient to be in a much safer position than before the operation. He did not see why, because clotting was induced by a foreign body, it should be a soft clot and remain so. He thought the clot, if it completely filled the aneurysm, would become hard. The results had shown firm clotting, with no liability to the production of emboli. Operative technique had greatly improved, and there was good reason to hope that such cases could be operated on without sepsis. If the surgeon could make sepsis a rarity, instead of a common occurrence, the operation would probably be attended with a very much smaller mortality, and possibly with a very much greater number of cures.

Dr. H. Stokes inquired as to the collateral circulation set up.

DR. IJUMSDEN, in reply, said that medical treatment of aneurysm in the past had been distinctly unsatisfactory. He had himself had four cases under his care-three men and one woman. The woman died suddenly six months after diagnosis, and no cause of death was discovered. One of the men died suddenly three months after diagnosis. There was no post-mortem, but he believed the aneurysm had burst. The third case had been operated on six years ago by Mr. Maunsell, who introduced twenty-four feet of wire, and performed electrolysis, but the aneurysm perforated through to the stomach, and the patient died about the fifth day. The post-mortem gave a beautiful picture of a lami- 
nated clot, showing the process of healing going on. The present patient had been getting worse before the surgeon took him over, and now he was much better, and he thought there was fair hope for the future.

Mr. Wheeler, in reply, said that death was the result in nearly every case without operative treatment. The postmortem, in cases where operation had been done, showed not a soft clot, but a laminated clot, sometimes consolidated altogether, so that he did not see how the operation could be regarded as unscientific. Collateral circulation was well established, though by what means he did not know. No cases published, without operation, showed any cures; while there had been cures in every series with operation, so that he thought the operation was undoubtedly justifiable.

\section{A Case of Thrombosis of the Superior Mesenteric Vein.}

Dr. J. J. Burgess read the account of a case of this lesion. [His paper will be found at page 114.] The interest in this individual case was the comparative mildness of the abdominal symptoms and the prominence of those of a cerebral type, so that the finding at the autopsy was a surprise. The very few cases of primary thrombosis of this vein was referred to from the lists of forty-one cases of Langdon Brown and sixty of Rolleston. The case was acute, and terminated fatally in eight days with gangrene of portion of the jejunum. The marked feature was the early development of coma, the partial recovery from which and its return with symptoms of cerebral compression, evidently. toxæmic.

Dr. Drury said it was only once in a lifetime that such cases were met with, and the paper should enable them to come to a reasonable conclusion if a similar case should happen to present itself.

Dr. Walter Smith said he had seen one or two cases of the condition, though not quite the same-the symptoms were more acute. In one case a correct diagnosis was made ante-mortem, relying on sudden abdominal pain and bloody stools. In Dr. Burgess's case the difficulties of correct diagnosis were almost insuperable. Thrombosis occurred in both mesenteric vessels, but there was a curious clinical difference between them-arterial mesenteric thrombosis was much more acute, and venous much more chronic in 
nature. The condition was rare, and it was very difficult to make out a cause for the thrombosis. The subject would, he thought, always remain one of difficulty, though possibly there might be a few cases in which an early diagnosis might be made, and surgical aid be called in.

The President said that about three years ago he saw, in consultation, a very stout, elderly lady, who had been suddenly attacked by vomiting, intense abdominal pain, and bloody diarrhœa, and they ventured on a diagnosis of thrombosis of the superior mesenteric artery. After death it was difficult to get a post-mortem, but the lady's medical attendant was able to make an incision with the ostensible object of relieving very extreme tympanites, and in this way he investigated the abdominal viscera, and found a very extensive gangrene of the intestine.

\section{A JOURNALISTIC VENTURE (OR ADVENTURE).}

A Journalust named Giloni, unusually well endowed with the enterprising spirit peculiar to that calling, determined to know something of lunatic asylums from within, with the humane idea to ameliorate the lot of the insane. He presented himself at the gate of the Cimarosa Asylum, and asked for an audience of the King of Italy. The attendants showed him the door; then he ran foul of the police, and finally got himself satisfactorily interned in the asylum. The doctors, evidently suspecting his good faith, began work on him with a powerful emetic; this was followed by a shower-bath, after which came vaccination. They held a consultation in the presence of the lunatic, and brutally but unanimously agreed that the patient was to be trephined for a cancer of the brain. By this time Signor Tommaso Giloni thought the best thing he could do was to confess; the doing which landed him in the police station. The magistrate, however, released him, concluding mercifully that he thought the doctors had administered sufficient punishment.-The Australasian Medical Gazette, Nov. 21, 1910. 